\title{
SOMOS TODOS REMATADOS CANALHAS: NOTAS SOBRE VINGANÇA E JUSTIÇA EM SHAKESPEARE
}

\author{
JOSÉ GARCEZ GHIRARDI ${ }^{1}$
}

\begin{abstract}
RESUMO: O tratamento que Shakespeare dá ao tema da vingança agrega enorme complexidade a esse gênero tão apreciado pelos elisabetanos. Em Hamlet e em Macbeth, por exemplo, os personagens não devem se confrontar apenas com a tensão tradicional entre ética cristã e ética da honra, que era habitual nesse tipo de peça. Eles se sentem oprimidos por um sentimento de que é o próprio sistema social que dá sentido a essa tensão que está ruindo, o que torna ação e inação igualmente sem sentido. A melancolia de Hamlet e o discurso de Malcolm dialogam com um conceito teológico central para a Reforma, a saber, a noção de que a natureza humana era irremediávelmente corrupta. Este artigo discute as implicações dramáticas desse conceito teológico, novo e controverso para a época, sobre a apresentação que Shakespeare faz da vingança.
\end{abstract}

PALAVRAS-ChaVE: Shakespeare; revenge plays; Lutero; Hamlet; Macbeth.

As revenge plays tão populares na Inglaterra elisabetana devem muito de sua força dramática ao fato de trazerem para o palco a violência de uma oposição entre dois códigos morais normativos para os contemporâneos de Shakespeare: a ética da honra, herdada do mundo medieval e que tinha raízes muito mais remotas, e a ética cristã, que há séculos vinha moldando cada aspecto da vida no Ocidente.

A ética da honra era constitutiva, indissociável daquilo que significava fazer parte da elite. Ela impunha aos membros de famílias nobres a obrigação de vingar a mínima afronta, real ou putativa. As narrativas homéricas, a história romana e os costumes medievais ofereciam exemplos abundantes do quão inescapável era para um verdadeiro nobre ser

\footnotetext{
${ }^{1}$ Doutor e Mestre em Estudos Linguísticos e Literários (USP). Graduado em Direito (USP). Professor da Escola de Direito de São Paulo (FGV/SP). E-mail: jose.ghirardi@fgv.br
} 
inflexível no zelo por sua reputação. Essa exigência transformava os palácios reais em palco de controvérsias intermináveis sobre os aspectos mais miúdos dos rituais que implicavam reconhecimento de precedência (lugar à mesa, ordem de entrada na procissão etc.) e de melindres infindáveis nas trocas sociais entres pares, que temiam sempre perder o prestígio social de que seu sustento dependia. O público de Shakespeare entenderia imediatamente o ressentimento de Iago contra Othello, pois conhecia uma infinidade de histórias sobre nobres se batendo por questões muito similares.

Em seu clássico $A$ crise da aristocracia, Lawrence Stone ressalta a centralidade da ética da honra para os cortesãos dos séculos XVI e XVII:

Um dos traços mais marcantes da época era a hipersensibilidade em relação à suprema importância da reputação. [...] O extraordinário código setecentista do duelo, a partir do qual os homens se sentiam impelidos a arriscar a vida por causa de uma observação casual, era apenas um crescimento canceroso dessa mesma célula ${ }^{2}$ (1967, p. 25, tradução minha).

Nobres que sofriam insultos não tinham a opção de perdoar o insolente, mesmo que desejassem fazê-lo por alguma razão pessoal ou política. A natureza pública da ofensa, que é da essência do insulto - eles são uma forma de negar ao outro o reconhecimento social que lhe é devido -, fazia do perdão uma impossibilidade. A perda de prestígio social era um dos reveses mais severos que alguém poderia sofrer, pois implicava gravíssimas consequências práticas em uma sociedade em que o acesso a cargos e rendas estava intimamente ligado ao reconhecimento social. Por isso, para que seu próprio status como nobreza não fosse colocado em risco, o bom cortesão era obrigado a buscar reparação mesmo daqueles que ele acreditava não terem jamais tido a intenção de ofendê-lo.

Como sugere, com lucidez característica, Baldesar Castiglione, a honra exigia ações que seriam consideradas tolas ou temerárias em outros contextos:

Tampouco deve [o bom cortesão] estar demasiado pronto a lutar, exceto quando a honra o exige; pois, além do

\footnotetext{
${ }^{2}$ No original: One of the most characteristic features of the age was its hyper-sensitivity upon the overriding importance of reputation. [...] The extraordinary seventeenthcentury code of the duel, under which men felt impelled to risk their lives to avenge a casual word, was merely a cancerous growth from the same cells.
} 
grande perigo que deriva da incerteza da Fortuna, merece grave censura, mesmo que obtenha sucesso, o homem que se lança a esses embates apressadamente e sem causa urgente. Mas quando ele se vê de tal modo comprometido que não pode recuar sem desdouro à sua reputação, ele deve ser o tão determinado quanto possa, tanto na preparação para o duelo, como no duelo em si, e sempre mostrar prontidão e $\operatorname{ousadia}^{3}$ (1967, p. 62, tradução minha).

Humildade cristã e amor fraternal não eram realmente virtudes para aquele que se encontrava no meio de batalhas encarniçadas para salvar a própria reputação e aumentar suas possibilidades de ascensão dentro da Corte.

O paradoxo, entretanto, residia no fato de que os mesmos nobres de que se exigia prontidão para a violência estavam, também, simultaneamente, e com igual força, obrigados a serem bons cristãos e, portanto, a abandonar qualquer pensamento de vingança contra aqueles que os insultassem. O mandamento de oferecer a outra face, expresso em Lucas VI, 29, era tão intrínseco à ideia prevalente do que significava seguir $o$ Cristo que não era possível desconsiderá-lo sem enorme custo social. Mesmo a Inglaterra protestante admirava a humildade de São Francisco de Assis (os franciscanos aparecem sempre sob uma luz positiva em Shakespeare) e a prática generalizada da penitência pública evidenciava a crença de que humilhar-se publicamente era um instrumento poderoso para aquela purificação espiritual sem a qual ninguém poderia salvar-se.

Oferecer a outra face, entretanto, emular a humildade franciscana ou aceitar humilhação pública, era exatamente o que um nobre não poderia fazer se desejava manter intactos sua reputação e status. A nobreza, mais do que qualquer outro grupo nesse período, se via premida pelo paradoxo de ter de buscar, simultaneamente, um reino que não é deste mundo e os favores políticos e econômicos de um monarca bem concretamente terreno.

Os nobres na Inglaterra elisabetana viam-se assim presos entre a obrigação de vingar e o comando de perdoar. Séculos de sobreposição de

3 No original: Nor should he [the good courtier] be too ready to fight except when honour demands it; for besides the great danger that the uncertainty of fate entails, he who rushes into such affairs recklessly and without urgent cause, merits the severest censure even though he be successful. But when he finds himself so far engaged that he cannot withdraw without reproach, he ought to be most deliberate, both in the preliminaries to the duel and in the duel itself, and always show readiness and daring. 
poder religioso e poder secular haviam criado uma coexistência instável entre dois poderosos modelos de conduta: o arrogante e melindroso Aquiles da Ilíada e o humilde e amável Cristo dos Evangelhos. As figuras do guerreiro compassivo e do rei santo, em que pese sua aguda contradição implícita, eram lugar comum nos discursos políticos e religiosos da época (Kantorowicz, 1957).

O oximoro wild justice (justiça selvagem) criado por Francis Bacon para se referir à vingança revela essa percepção social da ambiguidade insolúvel do problema de buscar reparação pelas ofensas sofridas. "A vingança é uma espécie de Justiça selvagem;" afirma Bacon em um tratado publicado em 1625, "e quanto mais a Natureza do homem a ela tende, mais deve a Lei reprimi-la. Pois o primeiro insulto apenas ofende a Lei; mas a Vingança desse insulto transforma a Lei em coisa inútil”4 (Bacon apud Callagghan, 2007, p. 39, tradução minha). A vingança era, assim, ao mesmo tempo selvagem (vale dizer, contrária ao que exigiam a razão e os bons costumes) e justiça (vale dizer, em harmonia com uma virtude desejada pela razão e pelos bons costumes).

O tema da vingança expandia o paradoxo cristão ao estabelecer uma tensão entre Direito e Natureza e ao tornar evidente a difícil coexistência entre os impulsos do homem natural, a racionalidade do bom súdito e a abnegação do bom cristão: não parece surpreendente que as plateias da época fossem apaixonadas por esse tema.

Nas tragédias de Shakespeare, entretanto, esse cabo de guerra entre valores igualmente poderosos se torna ainda mais complexo pelo sutil mas constante memento que o Bardo faz, a todo o tempo, da maldade humana: nossa vileza coloca em xeque a própria substância que compõe as duas éticas em conflito na Inglaterra elisabetana. No tratamento que Shakespeare dá ao tema da vingança, tanto a piedade cristã como o orgulho cortesão parecem funcionar fundamentalmente como fachada para ações absolutamente não-cristãs e para razões profundamente vis.

Como se pode ver em Hamlet, os altissonantes argumentos tradicionalmente invocados para justificar a necessidade de vingar as

\footnotetext{
4 No original: Revenge is a kinde of Wilde Justice which the more Mans nature runs to, the more ought Law to weed it out. For as for the first Wrong, it doth but offend the Law; but the Revenge of that wrong, putteth the Law out of Office.
} 
ofensas sofridas por uma linhagem nobre não sobrevivem a um escrutínio mais cuidadoso. Vistos de perto, eles se revelam como uma desculpa malajambrada para o exercício daquilo que a humanidade tem de pior: ódio, arrogância, ganância. A vingança, como sugerem as nuances do texto shakespeariano, não é a punição de um homem desonesto por um homem íntegro, mas, antes, um triunfo momentâneo de um miserável sobre outro. Enquanto trama a morte de Cláudio, o príncipe confessa a Ofélia sua vileza:

Eu também sou razoavelmente virtuoso. Ainda assim, posso acusar a mim mesmo de tais coisas que talvez fosse melhor minha mãe não me ter dado à luz. Sou arrogante, vingativo, ambicioso; com mais crimes na consciência do que pensamentos para concebê-los, imaginação para desenvolvê-los, tempo para executá-los. Que fazem os indivíduos como eu rastejando entre o céu e a terra? Somos todos rematados, canalhas, todos! Não acredite em nenhum de nós (Hamlet, III, 1).

A impiedosa invectiva de Hamlet contra a humanidade como um todo certamente soaria familiar aos ouvidos de seu público. Ela se nutria do conceito teológico da corrupção fundamental de todos os seres humanos, uma ideia central para o movimento da Reforma que, como se sabe, iria transformar para sempre a vida política da Inglaterra. Não se deve esquecer que Hamlet estudara na Universidade de Wittenberg, onde, em 1517, Lutero havia iniciado o tsunâmi teológico que transformaria para sempre a sociedade europeia. Shakespeare certamente tinha plena consciência do que o nome Wittenberg significava para espectadores protestantes e da capacidade que tal referência possuía de ligar sutilmente o pessimismo de Hamlet quanto à natureza humana às teses do iniciador da Reforma.

Como era de conhecimento geral, um argumento central (e supremamente controverso) para o edifício teológico construído por Lutero era o que postulava a "corrupção absoluta" dos seres humanos. Em seus escritos, cuja importância - assim como os de Calvino, alguns anos mais tarde - dificilmente pode ser exagerada, Lutero sustenta que o pecado original de tal modo corrompera a humanidade que não havia nada que qualquer cristão pudesse fazer para aumentar suas possibilidades de salvação, menos ainda para merecê-la. Apenas a fé nos méritos infinitos de 
Cristo poderia salvar a alma do fiel (Dickens, 1964)5. Adquirir o tipo correto de fé, entretanto, não era algo que se pudesse obter por meio do esforço próprio, pois essa era uma graça completamente independente da interferência humana. Acreditar que se podia avançar a causa da Própria salvação devido às boas obras praticadas era uma presunção estulta, um estratagema de Satanás para nos fazer colocar nossa esperança na carne, não em Deus.

É por isso que se atacava como particularmente nefasta a insistência Católica nas obras, que eram vistas como forma de juntar tesouros no céu (Mateus 6: 20). Ela era vista como derivada de uma compreensão equivocada da natureza humana, como uma arrogante presunção de que a conduta humana poderia impor-se à ação divina. Os líderes da Reforma acusavam-na de desencaminhar os fiéis, levando-os à falsa crença de que a oração, a penitência, o jejum e a esmola poderiam, por eles mesmos, ajudar a superar os limites da natureza decaída e conduzir à salvação. Segundo a teologia que se espalhava a partir de Wittenberg, não havia absolutamente nada que pudéssemos fazer para alterar nossa corrupção constitutiva Somos todos rematados canalhas! Não acredite em nenhum de nós.

O Tratado sobre as boas obras (1520), em que Lutero se dedica a explicar exatamente essa premissa crucial, tornou-se a perspectiva teológica hegemônica entre os adeptos da Reforma. Apenas a fé, não as obras, pode finalmente redimir a miséria humana:

Desse modo, como já indiquei, sempre louvei a fé e rejeitei todas as obras "que são feitas sem serem movidas por essa fé, a fim de afastar os homens de boas obras falsas, pretensiosas, farisaicas, desprovidas de fé, em que transbordam todos os mosteiros, igrejas, casas de ricos e pobres. [...] Em verdade, eles valorizam as obras acima de tudo, ao fazerem muitas, grandes e longas obras sem essa confiança, e eles pensam no bem apenas depois de realizarem tais obras; e, dessa forma, eles fundam sua confiança não na divina graça, mas nas obras, vale dizer, em areia e água e, por isto, eles irão finalmente sofrer uma queda cruel, como diz o Cristo, em Mateus, vii ${ }^{6}$ (Luther, 2015, tradução minha).

5 Sobre as visões religiosas em Shakespeare, ver Dutton, 2003.

6 No original: In this way I have, as I said, always praised faith, and I rejected all works which are done without such faith, in order thereby to lead men from the false, pretentious, pharisaic, unbelieving good works, with which all monastic houses, churches, homes, low and higher classes are overfilled, and lead them to the true, 
As implicações da crença na corrupção absoluta dos seres humanos iriam se mostrar profundas e duradouras, como atesta eloquentemente a obra de Hobbes. A necessidade de haver o Leviatã está ligada aos perigos de se deixar agir livremente o homem natural que é fundamentalmente mau. Nas peças de Shakespeare, essa perspectiva adiciona ainda mais complexidade ao já intricado tema da vingança.

Em Hamlet, a plateia vai aos poucos se dando conta de que a melancolia do príncipe tem como um de seus principais motivos o fato de que ele vê pouco sentido em vingar o assassinato de um pai que era, por sua vez, ele mesmo um assassino. Seu ato seria em última análise incapaz de produzir justiça ou, pior, acabaria por ampliar a corrupção reinante, tornando-o apenas mais um elo em uma longa cadeia de soberanos homicidas. Não importa o quanto os elaborados discursos fundados na tradição e no costume busquem apresentar a vingança como uma ação virtuosa e louvável, Hamlet continua enxergando o quanto de violência crua e egoísmo se esconde sob o manto do "dever de honra": "A face da rameira, embelezada por cosméticos, / Não é mais feia para a tinta que a ajuda / Do que meu feito pra minha palavra mais ornamentada"7 (Hamlet III, 1).

Entretanto, a despeito de toda a relutância que vem de suas reflexões filosóficas, Hamlet sabe muito bem que seus sentimentos privados e suas razões individuais não o eximem do dever de punir aquele que afrontou a honra de uma família nobre. Hamlet não pode perdoar Cláudio e seguir sendo um herói aos olhos da plateia mesmo que ela tenha claro o quanto ele abomina a tarefa que a convenção lhe impõe. Nem a indecisão atormentada do príncipe, nem seus solilóquios metafísicos podem ser compreendidos se não se observa que Hamlet sente, simultaneamente, a inevitabilidade do dever social da vingança e a falta de sentido de sua realização. O abismo entre ação e sentido espelha a distância entre a vingança e a natureza da justiça.

genuine, thoroughly good, believing works. [...] Indeed, they consider the works best of all, when they have done many, great and long works without any such confidence, and they look for good only after the works are done; and so they build their confidence not on divine favor, but on the works they have done, that is, on sand and water, from which they must at last take a cruel fall, as Christ says, Matthew vii.

7 No original: The harlot's cheek, beautied with plastering art, Is not more ugly to the thing that helps it/ Than is my deed to my most painted word. 
Por isso, um tema central da peça é a denúncia da impostura cruel das tradições - mais cruel porque inescapável. Pelo mesmo motivo, o foco se desloca do ato da vingança para seu agente, da suposta nobreza do gesto para a corrupção fundamental do vingador, mesmo quando ele parece virtuoso aos outros. Essa inflexão para a angústia permanente do personagem central e a sutil apresentação de nuances psicológicas em seus múltiplos conflitos internos antecipam leituras Modernas de subjetividade e identidade que, com o tempo, se mostrariam incompatíveis com o Ancien Régime (Taylor, 1992, p. 127-142).

Esse pessimismo em relação à humanidade como um todo tende a fazer tabula rasa das hierarquias sociais: em um mundo de pecadores, ninguém pode pretender-se melhor que o outro. $\mathrm{O}$ reconhecimento que nossa constitutiva miséria espiritual igualava rei e vilão vinha carregado de implicações politicamente perigosas (democráticas, revolucionárias), como o demonstra vividamente a Revolta dos Camponeses na Alemanha (15241525) e o movimento dos Levellers ao longo de toda a Revolução Puritana (Hill, 1972).

Além disso, o reconhecimento da depravação radical da humanidade funcionava não apenas para solapar as diferenças entre grupos hierarquicamente separados. Ele conduzia também à sugestão (perigosamente próxima às ideias de Maquiavel) que poderia não haver, de fato, diferença relevante entre o tirano sanguinário e o monarca piedoso. Essa proximidade desconfortável entre virtude e vício na realpolitik surge com clareza em outra obra-prima shakesperiana sobre o tema da vingança: A Tragédia de Macbeth.

Enquanto se prepara para atacar o nefasto Macbeth, Malcolm, o filho virtuoso que busca, com toda a justiça, vingar a morte do pai, revela a Macduff (e à plateia) um quadro bastante perturbador de seus sentimentos mais íntimos. Ele confessa a Macduff seu temor de que, após a queda do tirano, a Escócia possa sofrer ainda mais por força da maldade sem limites que dorme no coração do novo monarca.

MACDUFF

E quem será esse?

MALCOLM

Estou falando de mim mesmo, pessoa de quem conheço todos os vícios, dos maiores aos menores, vícios esses tão bem nutridos que, ao amadurecerem, farão o negro 
Macbeth parecer impoluto como a neve recém-caída. E o pobre Estado terá por ele estima, como um cordeirinho, se comparado com minhas ilimitadas iniquidades.

MACDUFF

Nem mesmo nas horrendas legiões do Inferno pode haver diabo tão amaldiçoado em suas maldades a ponto de suplantar Macbeth.

MALCOLM

Concordo: ele é sanguinário, devasso, avaro, falso, enganador, violento, maldoso, cheira a cada pecado que se pode nomear. Mas não há fim para a minha voluptuosidade. Nem todas as esposas, todas as filhas, matronas e donzelas de suas relações poderiam preencher o poço sem fundo de minha luxúria. E meu desejo derrubaria todos os impedimentos sequiosos de moderação que viessem contrapor-se ao meu apetite. Melhor Macbeth reinar que um homem assim ${ }^{8}$ (Macbeth, IV, 3).

A justificativa pífia que Malcolm oferece para seu discurso estarrecedor é a de que ele estava apenas testando a lealdade de Macduff, uma atitude bem pouco compreensível nesse ponto da ação. Em nenhum outro momento da peça se dera qualquer indicação de que Macduff não fosse absolutamente íntegro. Ao contrário: os eventos precedentes deixam pouca dúvida que ele também deseja vingar-se desse demônio que massacrou sua mulher e seus filhos.

\footnotetext{
8 No original:

MACDUFF:

What should he be?

MALCOLM

It is myself I mean: in whom I know

All the particulars of vice so grafted

That, when they shall be open'd, black Macbeth

Will seem as pure as snow, and the poor state

Esteem him as a lamb, being compared

With my confineless harms.

$M A C D U F F$

Not in the legions

Of horrid hell can come a devil more damn'd

In evils to top Macbeth.

MALCOLM

I grant him bloody,

Luxurious, avaricious, false, deceitful,

Sudden, malicious, smacking of every sin

That has a name: but there's no bottom, none,

In my voluptuousness: your wives, your daughters,

Your matrons and your maids, could not fill up

The cistern of my lust, and my desire

All continent impediments would o'erbear

That did oppose my will: better Macbeth

Than such an one to reign. [...].
} 
O discurso de Malcolm, assim, interrompe a narrativa dramática sem qualquer motivação externa relevante. Um interlúdio dramático semelhante, em que a ação é suspensa para revelar a consciência perturbada de um personagem, ocorrera um pouco antes na peça (I, 3), mas o protagonista aqui não é o impoluto filho de Duncan, mas o traiçoeiro Macbeth. Sonhando acordado com a grandeza que haviam lhe prometido as feiticeiras, Macbeth - agora Senhor de Cawdor - perde-se em seus pensamentos, abandona sem perceber os preparativos para a viagem próxima e, pensativo e imóvel, obriga todos os demais a acompanhá-lo inação. É Banquo quem o tira desse estupor autocentrado para conduzi-lo de volta à obrigação de agir.

A interrupção que Malcolm impõe à ação dramática por meio de um discurso extemporâneo se torna, assim, ainda mais carregada de prenúncios de mau agouro, uma vez que replica o mesmo conflito interior que levara Macbeth à sua decisão homicida. Uma vez que o veneno do desejo penetra a mente, o texto parece sugerir à plateia, seu efeito não pode ser interrompido - assim funciona nossa natureza corrompida. Ademais, esse tipo de introspecção por parte de Malcolm é ainda mais intrigante porque está meridianamente claro para o público qual o curso correto de ação: o príncipe deve cavalgar até Inverness e depor Macbeth.

As dúvidas internas do príncipe, sua introspecção atormentada, traz à mente, como já se apontou anteriormente, a ação suspensa em Hamlet. É o por quê? que se torna menos claro para ele quando enxerga, para lá da superfície, o contrassenso que se esconde no cerne da obrigação convencional de vingar. Não parece haver qualquer sentido em substituir Macbeth, por ele ser sanguinário, devasso, avaro, falso, enganador, violento, maldoso por alguém que se confessa pior do que ele. Somos todos rematados, canalhas, todos! Não acredite em nenhum de nós!

Assim, a noção teológica da corrupção radical da humanidade funciona nas peças de Shakespeare para colocar em dúvida a justiça da vingança, não porque haja qualquer incerteza quanto aos fatos ou ao autor da injúria. O olhar do Bardo sugere que a vingança perde sentido por um motivo muito mais grave: ela está ancorada em uma ordem sócio-política cujos fundamentos estão cedendo. Esse olhar mais amplo, é preciso 
enfatizar, é característico de Shakespeare e não um componente tradicional do gênero. Pelo contrário.

Embora o ato de vingança em si seja problemático, as revenge plays geralmente não questionam o sistema mais amplo a partir do qual ela faz sentido. As ambiguidades do tema podiam - e eram - exploradas para funcionar como um exemplo extremo do intratável (mas habitual) dilema da Cristandade: é preciso viver nesse mundo e renunciá-lo ao mesmo tempo9. Nas versões tradicionais desse impasse, a ação dramática segue de maneira bastante direta: embora sofrendo com os pruridos de consciência que vinham do embate entre a ética da honra e a ética cristã, o herói cumpria seu dever convencional como nobre, matando o culpado e fazendo surgir a paz ambígua da justiça selvagem.

As obras de Shakespeare nesse tema parecem substancialmente mais complexas porque essa ambiguidade convencional não é mantida dentro dos então prevalentes limites medievais. Nas tragédias shakespearianas, esses limites são ultrapassados de forma tão contundente que o que entra em discussão é o próprio sistema que lhes dá substância. Essa ampliação parece ser o que Jean Marino sugere quando observa que

As revisões que Shakespeare faz de Doutor Fausto e da Tragédia Espanhola são como a adição de novos aposentos a uma construção já existente. Suas revisões são semelhantes à incorporação de uma casa de campo do período Tudor a um edifício mais novo e mais amplo. A residência resultante preserva as características do original mas surge renovada e integrada em um todo maior e mais moderno ${ }^{10}$ (Marino, 2012, p. 325, tradução minha).

Os dois polos do dilema tradicional (ética da honra/ética cristã) parecem vazios a personagens que percebem o quão deslocados eles estariam em um mundo intrinsecamente corrupto. Apesar de toda a condenação oficial das agudas observações de Maquiavel (1990) - ou, quiçá, por força mesmo dessa condenação - seu diagnóstico do funcionamento do poder político se tornava cada vez mais crível para uma

9 Cf. 1 Corintios, 7: 31.

${ }^{10}$ No original: [Shakespeare's] revisions [of Doctor Faustus and The Spanish Tragedy] are like adding a new room to an existing building. Shakespeare's revisions are like incorporating a Tudor country house into a newer and grander edifice. The resulting house preserves features of the original but is renovated and integrated into a larger, more modern whole. 
Europa em que seguidas e brutais guerras por motivos religiosos corroíam os fundamentos mesmos dos discursos tradicionais que se valiam do sagrado para justificar o poder temporal. A denúncia do argumento tradicional como impostura ou incongruência ganhava terreno, e a compreensão das entranhas do poder dava peso à invectiva de Hamlet: Somos todos rematados, canalhas, todos! Não acredite em nenhum de nós!

O tratamento que Shakespeare dá à vingança é, desse modo, muito mais perturbador porque anuncia um problema mais amplo, que não pode ser corrigido pela punição de alguns. A melancolia de Hamlet, o discurso de Malcolm e a resignação estoica de Macbeth vão muito além da antinomia tradicional das revenge plays.

Essa impiedosa denúncia não era, contudo, apenas destrutiva, mas resultava de um entendimento da agência humana que se tornaria hegemônica no Ocidente. A sofisticação que Shakespeare instila em seus personagens dentro desse tema tradicional antecipa as consequências políticas da energia criativa liberada pelo terremoto teológico que a Reforma representou. A mesma força que abalara as crenças tradicionais abriu uma oportunidade para a emergência de novas crenças, para a ascensão de grupos sociais até então excluídos do poder. Edmundo, em Rei Lear, expressa claramente essa nova atitude ao pedir que os céus agora protejam os bastardos, isto é, aqueles que só contam com as próprias forças, e não com o respeito tradicional, para enfrentar as agruras da existência.

É possível sustentar que a ambiguidade de heróis e vilões em algumas das mais refinadas peças de Shakespeare (Hamlet, Macbeth, Otello, Rei Lear) deriva da incongruência entre as duas fontes de legitimação de comportamento que compunham a visão de mundo dominante na Inglaterra elisabetana: uma (medieval) ainda amplamente funcional como organizadora da sociedade (embora perdendo prestígio); outra (Moderna), ainda vista com suspeição (mas tornando-se cada vez mais apreciada). A ideia de corrupção radical, que Shakespeare articula em suas tragédias, levaria com o tempo ao declínio gradual das virtudes medievais baseadas na renúncia aos desejos (castidade, humildade, paciência etc.). Esse declínio não é tão surpreendente como poderia parecer. Se, como agora se pregava, as virtudes monásticas eram inúteis para nos conduzir à bem-aventurança 
na vida futura, então elas deveriam ser descartadas e substituídas por um conjunto de virtudes que pudesse, ao menos, permitir uma vida mais confortável no mundo presente (coragem, inteligência, iniciativa).

De modo algo paradoxal, a visão pessimista sobre a humanidade acabou por gerar aquilo que Charles Taylor (1992) chama de afirmação da vida comum, que ele vê como característica da Era Moderna e por fazer surgir um entendimento bastante positivo das possibilidades humanas. Essa nova valoração da vida quotidiana possivelmente tem papel central na transformação que, segundo Brian Morris, o teatro inglês sofreu após 1560: "Depois de 1560, surgem em número cada vez maior peças cujo interesse é secular. [...] As peças tendem a ser menos sobre virtudes e mais sobre pessoas"11 (Morris, 1971, p. 57, tradução minha).

Corolário dessa valoração da vida secular seria uma lenta - e supremamente controversa - reavaliação da dignidade do desejo e da vontade conforme se manifestavam no homem natural e o surgimento de novas leituras sobre o que significava uma ordem social justa. O tratamento soberbo que Shakespeare dá ao tema convencional da vingança captura, com absoluta sutileza, os embates ideológicos em um mundo que os elisabetanos viam como estando de ponta a cabeça e que nossos contemporâneos entendem como prelúdio da Modernidade. Não é surpresa que suas peças continuem sendo representadas para plateias imensas, séculos depois de $A$ tragédia espanhola, de Thomas Kyd, que, sendo tão popular à época (assim como tantas outras revenge plays), é hoje pouco mais que uma curiosidade da história literária.

\section{REFERÊNCIAS}

CALLAGHAN, Dympna; KYLE, Chris R. The wilde side of justice in early modern England and Titus Andronicus. In: JORDAN, Constance; CUNNINGHAM, Karen. The Law in Shakespeare. Basingstoke (England); New York: Palgrave Macmillan, 2007. (Bacon apud Callagghan, 2007.)

CASTIGLIONE, Baldesar The Book of the Courtier. England: Penguin Books, 1967.

DICKENS, A. G. Justification by Faith: Luther and Zwingli. In: . The English Reformation. Glasgow: Fontana, 1964.

${ }^{11}$ No original: After 1560 there appear more and more plays whose interests are secular. [...] Plays tend to be less about virtues than about people. 
DUTTON, Richard et al. (Org.) Theatre and Religion. Manchester: Manchester University Press, 2003.

GILLESPIE, Michael A. The Theological Origins of Modernity. Chicago: University of Chicago Press, 2008.

HILL, Christopher. The World Upside Down: Radical ideas during the English Revolution. London: Penguin, 1972.

KANTOROWICZ, Ernst H. The King's Two Bodies: A Study in Mediaeval Political Theology. Princeton: Princeton University Press, 1957.

LUTHER, Martin. A treatise on Good Works together with the Letter of Dedication by Dr. Martin Luther (1520). In: Adolph Spaeth, L.D. Reed, Henry Eyster Jacobs, et Al. (Ed.). Works of Martin Luther. Philadelphia: A. J. Holman Company, 1915. v. 1. p. 173-285. Disponível em: <http://www.iclnet.org/pub/resources/text/wittenberg/luther/worko2a.txt>. Acesso em: 20 fev. 2015.

MACHIAVELLI, Niccolò. The prince. 2. ed. Chicago: Encyclopaedia Britannica, 1990.

MARINO, James J. Middle Shakespeare. In: KENNEDY, Arthur F. (Ed). The Oxford Handbook of Shakespeare. Oxford: Oxford University Press, 2012.

MORRIS, Brian. Elizabethan and Jacobean Drama. In: RICKS, Christopher (Org). English Drama to 1710. London: Sphere Books, 1971.

SHAKESPEARE, W. Hamlet. Trad. de Millôr Fernandes. Porto Alegre: L\&PM Pocket, 1988.

SHAKESPEARE, W. Macbeth. Trad. de Millôr Fernandes. Porto Alegre: L\&PM Pocket, 1988.

STONE, Lawrence. The Crisis of Aristocracy - 1558-1641. Oxford: OUP, 1967.

TAYLOR, Charles. Sources of the Self: The Making of the Modern Identity. Cambridge: Cambridge University Press, 1992. 